\title{
A novel design of CTZS/Si tandem solar cell: A numerical approach
}

\section{Baseerat Bibi}

Dalian University of Technology School of Physics

\section{Bita Farhadi}

Dalian University of Technology School of Physics

\section{Waseem ur Rahman}

Dalian University of Technology Faculty of Mechanical Engineering Materials and Energy

\section{Aimin Liu ( $\square$ aiminl@dlut.edu.cn )}

Dalian University of Technology School of Physics

\section{Research Article}

Keywords: CZTS, Tandem, Solar cell. Simulation, SCAPS-1D

Posted Date: March 17th, 2021

DOl: https://doi.org/10.21203/rs.3.rs-309446/v1

License: (1) (1) This work is licensed under a Creative Commons Attribution 4.0 International License. Read Full License

Version of Record: A version of this preprint was published at Journal of Computational Electronics on July 16th, 2021. See the published version at https://doi.org/10.1007/s10825-021-01733-4. 


\section{Abstract}

Multijunction or tandem solar cells can split the solar spectrum over several subcells with different bandgaps to transform the sunlight into electricity more effectively than single-junction solar cells. The monolithic tandem design of third generation silicon solar energy materials is auspicious for photovoltaics. In this paper, the Simulation-based studies of copper zinc tin sulfide/Silicon (CZTS/Si) tandem cells based on CZTS as an upper subcell and silicon as a lower subcell absorber layer have been performed using SCAPS-1D. This study aims to evaluate the CZTS tandem cells' performance based on the fact that both subcells are simulated to produce the best efficiency recorded at its bandgap. The Simulation and optimization of the single junction CZTS and Si solar cells were initially performed to fit the state-of-art records efficiency of $11.65 \%$ and $18.7 \%$, respectively. Further, both the upper and lower cell has evaluated at different thicknesses for tandem configuration after validation. Also, to obtain the current matching condition for tandem structure, the upper subcell's performance is investigated at different thickness ranges from $0.1 \mu \mathrm{m}-1 \mu \mathrm{m}$ while keeping the lower subcell thickness at $80 \mu \mathrm{m}$. Thus, at optimized upper absorber thickness of $0.191 \mu \mathrm{m}$ and lower subcell $80 \mu \mathrm{m}$ at transmitted spectrum the current matching condition obtained and gave an efficiency of $10.6 \%$ and $11.9 \%$, respectively. The maximum efficiency of $\sim 23$ is obtained for tandem design with enhancing open circuit voltage $1.4 \mathrm{~V}$.

\section{Introduction}

Numerous studies to design tandem devices consist of subcells with various bandgaps have been conducted to exceed the efficiency of single-junction solar cells [1, 2]. Theoretically, infinite junction stacking under AM1.5 illumination can produce an efficiency of $65.4 \%$, and under a concentrated incident spectrum, it can enhance the efficiency up to $85 \%$ [3]. Typically, tandem structures of III-V/a-Si solar cells are manufactured to improve efficiency, and in fact, the cells with an efficiency of $46 \%$ and $13.6 \%$ have been illustrated that exceed single-junction solar cell efficiency [4].

In tandem device, various bandgap p-n junction solar cells to be stacked in a particular arrangement in which the upper cell absorbs high-energy photons equal to their absorber bandgap and the bottom sub-cell absorbed the remaining low-energy photons similar to their corresponding absorber band gaps [5]. This requirement brings numerous restrictions and obstacles to the development of a tandem solar device. A transparent tunnel junction connects the subcells, allowing the transmission of carriers and unabsorbed photons from the upper subcell through tunnel junction with minimal loss. Also, except for the significantly lower subcell, the upper subcells should be thinned appropriately to achieve a current matching condition between the subcells. In theory, the subcells in the tandem structure are electrically considered to be in a series connection, which means that the lowest current density subcell becomes the current limiting cell. Thus, ensure the most efficient tandem device by matching the subcells' current density [6, 7]. The concept of the tandem structure of III-V and a-Si solar cells has been presented over the past few decades [5]. Friedman et al. [8] have obtained an efficiency of $30 \%$ monolithic GalnP/GaAs tandem device and Gee et al. [9] recorded with an efficiency $31 \%$ of GaAs/Si mechanically stacked tandem device for concentrator applications. Theoretical studies of CGS/CIGS, InGaN/CIGS, InGaP/GaAs, indium gallium nitride 
(In0.48Ga0.52N/In $0.48 \mathrm{Ga} 0.52 \mathrm{~N}$ ), chalcopyrite/c-Si, and aSi:H/c-Si tandem device have also been reported by several researchers $[10-16]$.

Few studies have been conducted on Cu2ZnSnS4 (CZTS) based tandem solar cells then a-Si or III-V solar cells. The crystalline silicon solar cells efficiency is an approach to the upper limit predicted by this material's fundamental properties [17]. As a result, the Si (bottom cells) based tandem solar cells are essential, because they are the direct way to go beyond the single-junction efficiency limit. CZTS represents an exciting candidate for the upper subcell absorber because it consists of an abundant, non-toxic component and shows no stability problem under normal sunlight conditions [18]. A theoretical study of tandem Cu2ZnSn(S/Se)4 junction solar cells have been reported by Goutam Kumar et al. with maximum efficiency of $21.7 \%$ [19]. Also, Adeyinka D. et al. developed a monolithic tandem device based on CZTGS/CZTS and achieved $17.51 \%$ efficiency [20]. Recently, the first functioning monolithic CZTS/Si tandem cells have been ensured using a different intermediate connection between the subcells with Voc at around $948 \mathrm{mV}$ and an efficiency of 3.5\% [21]. Further, it was proposed to develop bottom Si cell protection strategies to obtain functioning monolithic CZTS/Si tandem cell. A comparative analysis of monolithic CZTS/Si tandem cells generates using different diffusion barrier layers based on TiN and solar cells are achieved which have a $V_{o c}$ of $1.06 \mathrm{~V}$, with good efficiency of $3.9 \%$ [22].

In this work, the CZTS/Si tandem device's potential efficiencies have examined using the SCAPS-1D simulation tool. Initially, the Simulation of single-junction CZTS based absorber layer solar cells and Sibased absorber layer solar cells has performed and validated against the simulated data. Further, the study has expanded for tandem solar cell structures to achieve improved photoconversion efficiencies. In tandem structure, the current matching condition has achieved with the variation of both subcells absorber layer thickness to enable the upper and lower subcells to have the same current density $\left(\mathrm{J}_{\mathrm{sc}}\right)$. The efficiency of tandem solar cells has limited by the relatively lower $\mathrm{J}_{\mathrm{sc}}$ of the upper subcells. Therefore, it must enhanced CZTS solar cells' efficiencies in advance to illustrate a CZTS/Si tandem solar cell that exceeds the device performance from an optimized single-junction solar cell.

\section{Methodology}

The optoelectronic performance of the considered tandem solar cell has studied by using Solar Cell Capacitance Simulator (SCAPS-1D, version 3.3.07) software under AM1.5 illumination. SCAPS is a onedimensional simulation tool with seven input semiconductor layers developed at the Department of Electronics and Information Systems, University of Gent, Belgium [23]. Furthermore, this software can measure precisely the open-circuit voltage, short-current density, quantum efficiency, fill factor, the band structure of heterojunctions, power conversion efficiency, spectral performance, electric field distribution, temperature, capacitance-voltage, generation and recombination profile, light bias, lighting from either the nside or p-side, and frequency spectroscopy [24] as compared to other simulation software such as; Aestimo [25], PC1D [26], GPVDM [27] AFORS-HET [28].

The material considered for the comprehensive study of a single-junction and tandem configuration is CZTS and Si with a bandgap of $1.55 \mathrm{eV}$ and $1.1 \mathrm{eV}$ respectively. The upper subcell structure consists of an 
efficient layer such as ZnO:Al, i-ZnO, ZnMgO, and CZTS as shown in Fig. 1(a). A p-type CZTS semiconductor is used as an absorber layer for producing a carrier with the least absorbed light reflection and the lowest transmission losses [29]. The $\mathrm{ZnO}$ serves as a window layer because of its high $\mathrm{n}$-type conductivity and wide bandgap [30] and n-type $\mathrm{ZnMgO}$ is used as a buffer layer. Thus, a buffer layer creates a junction along with the absorber layer to reduce absorption losses and direct the produced carrier to the electrodes. Whereas, the buffer layer will minimize surface losses along with the window layer [31]. Moreover, ZnMgO has a wide bandgap and as a buffer layer leads to reduce the recombination [32]. Also, ZnMgO as buffer layer has a perfect lattice match with the i-ZnO and ZnO:Al window layer [33, 34]. Similarly, the bottom subcell consisted of front contact, n-Si, p-Si, $\mathrm{p}^{++}-\mathrm{Si} /$ back contact as shown in Fig. 1(b). TiN is use as front contact of lower subcell with work function of $4.3 \mathrm{eV}$ because of its excellent chemical and thermal stability and quasi-metallic conductivity and as a copper diffusion barrier for interconnect technologies[35, 36]. A highly doped Back Surface Field (BSF) $\mathrm{p}^{++}-$Si used to minimize carrier recombination losses on the rear surface.

In the first step, the simulations of single-junction CZTS and Si solar cells were performed under the standard AM1.5 spectrum, and results are validated against the simulated data reported by[12, 37]. Further, the tandem design CZTS/ Si has presented in Fig. 1(c). The CZTS/Si tandem device has an ideal tunnel junction to have the same current density value in both subcells. However, because of the limitations of the SCAPS-1D simulator, between the upper and lower subcells, the ideal tunnel junction without optoelectric losses has presumed. It is essential to achieve a current matching condition between the cells to conduct the tandem design study. Thus, both cells has independently simulated with different illumination range. The upper subcell's current density and the transmitted spectra for the lower subcell have calculated by adjusting the upper subcell absorber layer thicknesses range from $0.1 \mu \mathrm{m}$ to $1 \mu \mathrm{m}$. The transmitted spectrum was then used as the lower Si subcell of the input illumination spectrum. Next, determined the lower subcell $\mathrm{J}_{\mathrm{sc}}$ values, and then each of the current matching points was calculated. A similar method is commonly used for reporting tandem design simulation using the SCAPS-1D $[12,19]$. The material properties in Table 1 are taken from the literature and are used to simulate the photovoltaic response of the considered single and tandem solar cell [33, 38-45], whereas the optical absorption coefficients of CZTS are taken from file [46] and other are from SCAPS-1D, are presented in Fig. 2. Table 2 shows the basic equations for the SCAPS-1D and transmitted spectrum $[47,48]$. 
Table 1

Material parameters used in single Junction tandem solar cell simulation

\begin{tabular}{|c|c|c|c|c|c|c|c|}
\hline $\begin{array}{l}\text { Material } \\
\text { Properties }\end{array}$ & $\begin{array}{l}\text { Window } \\
\text { Layer } \\
\text { ZnO }\end{array}$ & $\mathrm{i}: Z n 0$ & ZnMgO & CZTS & Si (n) & Si $(p+)$ & $\mathrm{Si}\left(\mathrm{P}^{++}\right)$ \\
\hline $\begin{array}{l}\text { Thickness } \\
\mathrm{d}(\mu \mathrm{m})\end{array}$ & 0.01 & 0.02 & 0.02 & variable & 0.02 & 80 & 0.1 \\
\hline $\begin{array}{l}\text { Bandgap } \\
\text { (eV) }\end{array}$ & 3.37 & 3.3 & 3.32 & 1.55 & 1.1 & 1.1 & 1.1 \\
\hline $\begin{array}{l}\text { Electron } \\
\text { affinity } \\
\bigotimes(e V)\end{array}$ & 4.45 & 4.6 & 4.53 & 4.5 & 4.05 & 4.05 & 4.05 \\
\hline $\begin{array}{l}\text { Relative } \\
\text { permittivity } \\
(\varepsilon)\end{array}$ & 9 & 9 & 9 & 10 & 11.9 & 11.9 & 11.9 \\
\hline $\begin{array}{l}\text { Conduction } \\
\text { band } \\
\text { effective } \\
\text { density of } \\
\text { states } \\
\left(\mathrm{cm}^{-3}\right)\end{array}$ & $2.2 \times 10^{18}$ & $2.2 \times 10^{18}$ & $2.2 \times 10^{18}$ & $2.2 \times 10^{18}$ & $2.8 \times 10^{19}$ & $2.8 \times 10^{19}$ & $2.8 \times 10^{19}$ \\
\hline $\begin{array}{l}\text { Valence } \\
\text { band } \\
\text { effective } \\
\text { density of } \\
\text { states } \\
\left(\mathrm{cm}^{-3}\right)\end{array}$ & $1.8 \times 10^{19}$ & $1.8 \times 10^{19}$ & $1.8 \times 10^{19}$ & $1.8 \times 10^{19}$ & $2.6 \times 10^{19}$ & $2.6 \times 10^{19}$ & $2.6 \times 10^{19}$ \\
\hline $\begin{array}{l}\text { Electron } \\
\text { mobility } \mu \mathrm{n} \\
\left(\mathrm{cm}^{2} / \mathrm{Vs}\right)\end{array}$ & $1.00 \times 10^{2}$ & $1.00 \times 10^{2}$ & $1.00 \times 10^{2}$ & $1.00 \times 10^{2}$ & $1.041 \times 10^{3}$ & $1.041 \times 10^{3}$ & $1.041 \times 10^{3}$ \\
\hline $\begin{array}{l}\text { Hole } \\
\text { mobility } \mu \mathrm{P} \\
\left(\mathrm{cm}^{2} / \mathrm{Vs}\right)\end{array}$ & $2.5 \times 10^{1}$ & $2.5 \times 10^{1}$ & $2.5 \times 10^{1}$ & $3.5 \times 10^{1}$ & $4.21 \times 10^{2}$ & $4.21 \times 10^{2}$ & $4.21 \times 10^{2}$ \\
\hline $\begin{array}{l}\text { Donor } \\
\text { density ND } \\
\left(\mathrm{cm}^{-3}\right)\end{array}$ & $1.0 \times 10^{20}$ & $1.0 \times 10^{18}$ & $1.0 \times 10^{20}$ & $1.0 \times 10^{1}$ & $8.0 \times 10^{20}$ & $1.0 \times 10^{1}$ & $1.0 \times 10^{1}$ \\
\hline $\begin{array}{l}\text { Acceptor } \\
\text { density NA } \\
\left(\mathrm{cm}^{-3}\right)\end{array}$ & $0.0 \times 10^{0}$ & $0.0 \times 10^{0}$ & $1.0 \times 10^{0}$ & $1.0 \times 10^{17}$ & $1.0 \times 10^{1}$ & $5.0 \times 10^{18}$ & $1.0 \times 10^{22}$ \\
\hline
\end{tabular}


Table 2: Basic equations for the SCAPS-1D, transmitted spectrum and computing efficiency

One dimension

semiconductor

Equation

Beer Lambert

Model

$$
S(\lambda)=S_{v}(\lambda) \cdot \exp \left(\sum_{i=1}^{4}-\left(\alpha_{i}(\lambda)\right) \cdot d_{i}\right)
$$

FF and efficiency of solar cell

$$
\begin{gathered}
F F=\frac{V_{\max } \times I_{\max }}{V_{o c} \times J_{s c}} \\
\eta=\frac{V_{o c} \times J_{s c} \times F F \times \mathbf{1 0 0}}{P_{\text {in }}}
\end{gathered}
$$
Where $\varepsilon$, and $\varepsilon$ stands for
vacuum and relative permittivity, $\Psi$ is electric potential, $q$ is the electronic charge, $\mathrm{p}$ and $\mathrm{n}$ are the free hole and free electron, $\mathrm{p}_{\mathrm{t}}$ and $\mathrm{n}_{\mathrm{t}}$ stand for trap hole and trap electron, $\mathrm{N}_{d}$ stands for ionized donors density and $\mathrm{N}_{2}$ stands for ionized acceptors density. The parameter $\mathrm{J}_{\mathrm{n}}$ represents the electron current density and $\mathrm{J}_{\mathrm{p}}$ represents the hole current density. Whereas, $\mu_{\mathrm{n}}, \mu_{p}$, $E F_{n}$ and $E F_{p}$ stand for electron mobility, hole mobility, quasi electron Fermi level, and hole quasi Fermi-level.

Where, $\boldsymbol{S}$, is the AM1.5 sun spectrum, $\alpha_{i} \quad$ stands for absorption coefficient and $d$ present the respective layer thickness

The optimal point between $\mathrm{V}=0$ and $\mathrm{V}=\mathrm{V}_{\mathrm{oc}}$ is $\mathrm{V}_{\max }$, whereas, $\mathrm{I}_{\max }$ relates with $V_{\operatorname{mas}}$.

\section{Results And Discussion}

This section is categorized in three subsections: the standalone performance of the single junction upper and lower subcell is presented in Sect. 3.1. Effects of absorber layer thickness on upper and lower sub-cell under standalone conditions are introduced in Sect. 3.2. The performance of the CZTS-Si tandem solar cell is addressed in Sect. 3.3.

\subsection{The standalone performance of the single junction upper and lower cell}

In this section, the upper and lower subcell's validation with the numerically simulated solar cell reported in the previously published data is presented. The current density-voltage $(\mathrm{J}-\mathrm{V})$ characteristics of the single junction upper and lower cell are obtained in this respect and are stated in Fig. 3. The results presented in Fig. 3 show that the short circuit current density of upper and lower subcell is $20.5 \mathrm{~mA} / \mathrm{cm}^{2}$ and 36.9 
$\mathrm{mA} / \mathrm{cm}^{2}$ while the $\mathrm{V}_{\mathrm{oc}}$ in the individual cells is $0.7 \mathrm{~V}$ and $0.639 \mathrm{~V}$. The photovoltaic parameters are summarized and compare against the previously published simulated data in Table 3.

Table 3

Comparison of the photovoltaic parameter of single-junction CZTS and Si solar cell

\begin{tabular}{|llllll|}
\hline & Voc $(\boldsymbol{N})$ & $J_{\text {sc }}\left(\mathbf{m A} / \mathbf{c m}^{2}\right)$ & FF (\%) & PCE (\%) & Ref \\
\hline CZTS-based absorber layer solar cell & 0.70 & 20.52 & 80.74 & 11.65 & Present work \\
\hline CZTS-based absorber layer solar cell & 0.78 & 21.32 & 68.78 & 11.42 & {$[32]$} \\
\hline Si-based absorber layer solar cell & 0.6433 & 35.04 & 83.39 & 18.8 & Present work \\
\hline Si-based absorber solar cell & 0.639 & 36.9 & 79.4 & 18.7 & [12] \\
\hline 3.2. Effect of absorber layer thickness On upper and lower \\
Subcells the under standalone condition
\end{tabular}

The upper and lower solar cells are investigated first with different absorber layer thickness to evaluate the CZTS-Si tandem device's performance. The J-V characteristic of upper and lower subcell with different absorber layer thickness is depicted in Fig. 4 under AM1.5 illuminations. It is obtained that an increase in the thickness of the active layer of the upper subcell substantially increases the current density shown in Fig. 4(a). This enhancement is due to improved optical absorption that further leads to increased production of electron-hole pairs. The $\mathrm{J}_{\mathrm{sc}}$ of the device is increased by the resultant separation of produced electron-hole pairs. It is observed that at lower thicknesses, the improvement in $\mathrm{J}_{\mathrm{sc}}$ is substantial however, it begins to saturate at greater thicknesses as depicted in Fig. 4(a). Quantitatively, improvement of $17.9 \%$, $14.9 \% \mathrm{t}$ and $9.5 \%$ in $\mathrm{J}_{\mathrm{sc}}$ was computed when raising the upper cell's thickness of from $0.1 \mu \mathrm{m}$ to $0.2 \mu \mathrm{m}$, $0.2 \mu \mathrm{m}$ to $0.3 \mu \mathrm{m}$, and $0.3 \mu \mathrm{m}$ to $0.4 \mu \mathrm{m}$ respectively. Whereas $2.1 \%, 1.8 \%$, and $1 \%$ rise in $\mathrm{J}_{\mathrm{sc}}$ are evaluated in lower subcell thickness. Figure 4(b) depicts that there is no major effect of thickness on the $\mathrm{J}_{\mathrm{sc}}$ of the lower subcell; however, a slight increase in thickness is observed approaching the optimum value of $\mathrm{J}_{\mathrm{sc}}$ for CZTS.

Furthermore, both devices' PV parameters are computed at different absorber layer thickness to summarize their performance, and the results are plotted in Fig. 5. It has been found that $\mathrm{V}_{\mathrm{oc}}$ of CZTS increases with increasing thickness from $0.1 \mu \mathrm{m}$ to $0.2 \mu \mathrm{m}$ and saturates with a further increase of thickness while the Sibased solar cell does not have a major thickness impact on $V_{\text {oc }}$ and a marginal increase with thickness is observed. The $\mathrm{J}_{\mathrm{sc}}$ of CZTS based solar cell shows a significant increase with the absorber layer's thickness, while in Si-based solar cell $J_{s c}$ does not show a significant increase with thickness. Also, FF shows the same behavior as the $\mathrm{V}_{\mathrm{oc}}$ of both cells. It is evaluated that both cells conversion efficiency is improved from 2.8\% (upper subcell) and 21.3\% (lower subcell) to 18\% (upper subcell) and 21.4\% (lower subcell) by increasing the thickness from $0.1 \mu \mathrm{m}$ to $1.0 \mu \mathrm{m}$ for upper subcell and $10 \mu \mathrm{m}$ to $250 \mu \mathrm{m}$ for lower subcell respectively. 


\subsection{CZTS-Si tandem solar cell}

A tandem solar cell simulation was performed by employing a wide bandgap CZTS based subcell on the narrow bandgap silicon-based subcell, separated by TiN is the front contact of lower subcell. For simulating CZTS/Si tandem solar cells, a straightforward technique was used. First, the AM1.5 sun spectrum is incident on the upper cell's front surface, and the transmitted spectra are computed by using the thickness and absorption coefficient of each layer of the upper cell. Next, the transmitted spectrum used as incident illumination of the lower Si-based subcells. The upper subcell was initially simulated by changing the absorber layer thickness from $0.1 \mu \mathrm{m}-1 \mu \mathrm{m}$, while the other layer thickness in the upper subcell remains fixed. The transmitted spectrums filtered by the upper subcell with different absorber layer thicknesses are shows in Fig. 6(b). These transmitted spectrums are then use to illuminate the lower subcell to achieve the current matching. If the $\mathrm{J}_{\mathrm{sc}}$ value for the upper and lower subcells is the same, the current match condition is defined [49]. Two-terminal tandem devices operate electrically as two diodes connected in series, so the same current must pass from each subcell because this arrangement's electrical properties. In contrast, the

total voltage drop equals the sum of each cell's voltage drop across the tandem device [50]. The tandem $\mathrm{J}_{\mathrm{sc}}$ follows the lower value of subcell connected in series [51]. When the upper subcell thickness increases beyond the optimized value, the $\mathrm{J}_{\mathrm{sc}}$ of the upper subcell increases, whereas the lower cell $\mathrm{J}_{\mathrm{sc}}$ is reduced. This is due to the absorption of more photons by thicker upper subcell and less light is transmitted to the lower subcell. Thus, the overall current density of tandem cells decreases [20]. The same phenomenon happens when the upper subcell thickness is less than the optimized value; less absorption occurs in the upper subcell, which reduceses the overall tandem current density. Because of the mentioned phenomena above, the current matching condition is accomplished by using the filtered spectrum shown in Fig. 6(c). The calculated transmitted spectrums at different upper cell thicknesses are illuminated on the lower subcell's front surface and evaluate the PV parameters. Furthermore, to adjust the lower cell thickness, it has been done by varying the lower cell thickness from $10 \mu \mathrm{m}-250 \mu \mathrm{m}$ in 8 equal steps. At an optimal value, the upper subcell at $0.191 \mu \mathrm{m}$ and lower subcell at $80 \mu \mathrm{m}$ the current matching establishes with a current of $19.3 \mathrm{~mA} / \mathrm{cm}^{2}$.

Additionally, the remaining PV parameters under the filtered spectrum from lower subcell are also obtained, as shown in Fig. 7(a-d). It is observed from Fig. 7(a) that the value of $\mathrm{J}_{\mathrm{sc}}$ is higher at the low thickness of the upper subcell, which begins to decrease as the absorber layer thickness increase and found the current matching condition. A slight influence on $V_{\text {oc }}$ and FF is also observed in Fig. 7(b, d). The PCE under transmitted spectrum decreases with upper subcell thickness shown in Fig. 7 (d).

The tandem cell's J-V curve at $0.191 \mu \mathrm{m}$ thick CZTS upper cell and $80 \mu \mathrm{m}$ silicon lower cell are shown in Fig. 8, along with the upper and lower subcell in tandem structure with current matching. The JV curve of both upper and lower subcells, measured separately at the same current, is added together in series to compute tandem device's JV characteristics of the $[12,50]$. In terms of higher-open circuit voltage, which is the sum of the upper and lower cells' open-circuit voltages, the tandem device's significance can be observed. The maximum current in the tandem cell configuration is limited by the current in the CZTS upper subcell. This helped to achieve a higher $\mathrm{V}_{\text {oc }}$ with an optimum current density for the complete tandem 
structure. The PV parameters of the upper cell, lower cell, and tandem device with the current matching condition are shown in Table 4. For the optimized CZTS/Si tandem structure, the investigated device configuration's maximum efficiency is achieved by approximately $23 \%$.

Table 4

PV parameter of optimized upper, lower and tandem solar cell configuration

\begin{tabular}{|lllll|}
\hline Solar Cell & Voc $(v)$ & Jsc $\left(\mathrm{mA} / \mathrm{cm}^{2}\right)$ & FF (\%) & PCE (\%) \\
\hline CZTS upper subcell in a tandem structure & 0.7098 & 19.38 & 76.66 & 10.6 \\
\hline Si lower subcell in a tandem structure & 0.6992 & 19.34 & 83.48 & 11.93 \\
\hline Tandem cell & 1.4 & 19.38 & 83.5 & 22.9 \\
\hline
\end{tabular}

Eventually, in Table 5 the comparative study of present work with those related in previous work has been shown. Our proposed model that consist of earth abundant and non-toxic Si and CZTS as a absorber layer and $\mathrm{ZnMgO}$ as a buffer layer rather than toxic CdS supports high voltage, current density, fill factor, efficiency.

Table 5

Comparison of PV parameter of present work with other Tandem structure from literature

\begin{tabular}{|llllll|}
\hline Structure & Voc $(\mathrm{V})$ & $\mathrm{Jsc}\left(\mathrm{mA} / \mathrm{cm}^{2}\right)$ & FF (\%) & PCE & Ref \\
\hline CIGS/Si & 1.25 & 15.80 & 81.50 & 19.8 & {$[12]$} \\
\hline CZTS/CZTSe & 1.32 & 20.98 & 78.20 & 20.87 & {$[19]$} \\
\hline CZTS/Si & 1.4 & 19.38 & 83.5 & 22.9 & Present work \\
\hline
\end{tabular}

\section{Conclusions}

The investigation CZTS / Si tandem solar cell consists of CZTS-based upper subcell and Si-based lower subcell has been carried out by SCAPS-1D simulation tool. The upper and lower cell condition was simulated individually based on the state-of-art records with the conversion efficiency of $11.65 \%$ and $18.7 \%$. Further, the upper and lower subcell are evaluated at different thickness range from $0.1 \mu \mathrm{m}-1 \mu \mathrm{m}$ and $10 \mu \mathrm{m}$ $250 \mu \mathrm{m}$ respectively for tandem arrangement. Moreover, the current matching condition has been examined for a realistic tandem approach by adjusting the absorber layer's thickness in upper subcell. Thus, at optimized upper subcell absorber layer thickness of $0.191 \mu \mathrm{m}$ and lower subcell $80 \mu \mathrm{m}$ at transmitted spectrum, the current matching condition is obtained and gave an efficiency of $10.6 \%$ and $11.9 \%$, respectively. The tandem cell's $\mathrm{J}-\mathrm{V}$ curve is obtained by adding the $\mathrm{J}-\mathrm{V}$ curve of upper subcell at AM1.5 and the lower subcell at transmitted spectrum at equal current. The current study showed the PV parameter Voc $=1.4 \mathrm{v} \mathrm{jsc}=19.38 \mathrm{~mA} / \mathrm{cm}^{2}, \mathrm{FF}=83.5 \%$ with an optimum efficiency of about $23 \%$ for CZTS $/ \mathrm{Si}$ tandem design. This present study demonstrates that a CZTS / Si tandem design improves the CZTS single-junction solar cell performance due to the absorption of more solar photons. 


\section{Declarations}

\section{Acknowledgment}

This work was supported by the Research Program of the School of Physics, Dalian University of Technology, China

\section{Data Availability Statement}

All data generated or analysed during this study are included in this published article.

\section{References}

1. Luque, A. and A. Mart, Theoretical limits of photovoltaic conversion and new-generation solar cells. Handbook of Photovoltaic Science and Engineering, John Wiley \& Sons, Ltd, 2011: p. 130-168.

2. Friedman, D., et al., High-efficiency III-V multijunction solar cells. Handbook of Photovoltaic Science and Engineering, 2011: p. 314-364.

3. Marti, A. and G.L. Araújo, Limiting efficiencies for photovoltaic energy conversion in multigap systems. Solar Energy Materials and Solar Cells, 1996. 43(2): p. 203-222.

4. Green, M.A., et al., Solar cell efficiency tables (version 54). Progress in photovoltaics: research and applications, 2019. 27(7): p. 565-575.

5. Sayad, Y., Photovoltaic potential of III-nitride based tandem solar cells. Journal of Science: Advanced Materials and Devices, 2016. 1(3): p. 379-381.

6. Shafarman, W. and P. Paulson. Losses in CulnSe/sub 2/-based thin film monolithic tandem solar cells. in Conference Record of the Thirty-first IEEE Photovoltaic Specialists Conference, 2005. 2005. IEEE.

7. Nishiwaki, S., et al., A stacked chalcopyrite thin-film tandem solar cell with $1.2 \mathrm{~V}$ open-circuit voltage. Progress in Photovoltaics: Research and Applications, 2003. 11(4): p. 243-248.

8. Friedman, D., et al., Accelerated publication 30.2\% efficient GalnP/GaAs monolithic two-terminal tandem concentrator cell. Progress in Photovoltaics: Research and Applications, 1995. 3(1): p. 47-50.

9. Gee, J.M. and G.F. Virshup. A 31\%-efficient GaAs/silicon mechanically stacked, multijunction concentrator solar cell. in Conference Record of the Twentieth IEEE Photovoltaic Specialists Conference. 1988. IEEE.

10. Nacer, S. and A. Aissat, Simulation and optimization of current matching double-junction InGaN/Si solar cells. Applied Physics A, 2016. 122(2): p. 138.

11. Marouf, Y., L. Dehimi, and F. Pezzimenti, Simulation study for the current matching optimization in InO. 48Ga0. 52N/InO. 74GaO. 26N dual junction solar cells. Superlattices and Microstructures, 2019. 130: p. 377-389.

12. Kim, K., et al., Simulations of chalcopyrite/c-Si tandem cells using SCAPS-1D. Solar Energy, 2017. 145: p. 52-58. 
13. Bencherif, H., et al., Improving the efficiency of a-Si: $\mathrm{H} / \mathrm{c}$-Si thin heterojunction solar cells by using both antireflection coating engineering and diffraction grating. Optik, 2019. 182: p. 682-693.

14. Farhadi, B. and M. Naseri, An optimized efficient dual junction InGaN/CIGS solar cell: A numerical simulation. Superlattices and Microstructures, 2016. 96: p. 104-110.

15. Farhadi, B. and M. Naseri, A novel efficient double junction InGaP/GaAs solar cell using a thin carbon nano tube layer. Optik, 2016. 127(15): p. 6224-6231.

16. Farhadi, B. and M. Naseri, Structural and physical characteristics optimization of a dual junction CGS/CIGS solar cell: A numerical simulation. Optik, 2016. 127(21): p. 10232-10237.

17. Yoshikawa, K., et al., Silicon heterojunction solar cell with interdigitated back contacts for a photoconversion efficiency over 26\%. Nature energy, 2017. 2(5): p. 1-8.

18. Song, N., et al., Study of sputtered Cu2ZnSnS4 thin films on Si. Applied Surface Science, 2018. 459: p. 700-706.

19. Gupta, G.K. and A. Dixit, Theoretical studies of single and tandem Cu2ZnSn (S/Se) 4 junction solar cells for enhanced efficiency. Optical Materials, 2018. 82: p. 11-20.

20. Adewoyin, A.D., et al., Development of CZTGS/CZTS tandem thin film solar cell using SCAPS-1D. Optik, 2019. 176: p. 132-142.

21. Valentini, M., et al., Fabrication of monolithic CZTS/Si tandem cells by development of the intermediate connection. Solar Energy, 2019. 190: p. 414-419.

22. Martinho, F., et al., Nitride-based interfacial layers for monolithic tandem integration of new solar energy materials on Si: the case of CZTS. ACS Applied Energy Materials, 2020. 3(5): p. 4600-4609.

23. Burgelman, M., P. Nollet, and S. Degrave, Modelling polycrystalline semiconductor solar cells. Thin solid films, 2000. 361: p. 527-532.

24. Shalav, A., et al., Application of NaYF 4: Er 3+ up-converting phosphors for enhanced near-infrared silicon solar cell response. Applied Physics Letters, 2005. 86(1): p. 013505.

25. Cetinkaya, C., et al., Optical properties of n-and p-type modulation doped GaAsBi/AlGaAs quantum well structures. Journal of Alloys and Compounds, 2018. 739: p. 987-996.

26. Hashmi, G., et al., Study of the enhancement of the efficiency of the monocrystalline silicon solar cell by optimizing effective parameters using PC1D simulation. Silicon, 2018. 10(4): p. 1653-1660.

27. Mäckel, H. and R.C. MacKenzie, Determination of charge-carrier mobility in disordered thin-film solar cells as a function of current density. Physical Review Applied, 2018. 9(3): p. 034020.

28. Yao, Y., et al., Enhanced efficiency in bifacial HIT solar cells by gradient doping with AFORS-HET simulation. Materials Science in Semiconductor Processing, 2018. 77: p. 16-23.

29. Bhalerao, A.B., C. Lokhande, and B. Wagh, Photoelectrochemical cell based on electrodeposited nanofibrous ZnS thin film. IEEE transactions on nanotechnology, 2013. 12(6): p. 996-1001.

30. Ueda, K., H. Tabata, and T. Kawai, Magnetic and electric properties of transition-metal-doped ZnO films. Applied Physics Letters, 2001. 79(7): p. 988-990.

31. Mostefaoui, M., et al., Simulation of high efficiency CIGS solar cells with SCAPS-1D software. Energy Procedia, 2015. 74: p. 736-744. 
32. Hu, Y., et al., The impact of $M g$ content on the structural, electrical and optical properties of MgZnO alloys: a first principles study. Current Applied Physics, 2015. 15(3): p. 423-428.

33. He, X., et al., Simulation of high-efficiency CdTe solar cells with Zn1-xMgxO window layer by SCAPS software. Materials Research Express, 2018. 5(6): p. 065907.

34. Wang, H.-C., et al., Synthesis and characterization of ZnO/ZnMgO multiple quantum wells by molecular beam epitaxy. Optical Materials Express, 2013. 3(2): p. 237-247.

35. Yoon, D.-S., et al., Enhanced thermal stability of a sputtered titanium-nitride film as a diffusion barrier for capacitor-bottom electrodes. Journal of electronic materials, 2003. 32(8): p. 890-898.

36. Yang, X., et al., Dual-function electron-conductive, hole-blocking titanium nitride contacts for efficient silicon solar cells. Joule, 2019. 3(5): p. 1314-1327.

37. Bahfir, A., M. Boumaour, and M. Kechouane, Prospects of potential ZnMgO front layer in CZTS solar cells. Optik, 2018. 169: p. 196-202.

38. Černivec, G., A. Jagomägi, and K. Decock, Analysis of CZTSSe monograin layer solar cells. 2011.

39. Altamura, G., Development of CZTSSe thin films based solar cells. 2014, Université Joseph-FourierGrenoble I.

40. Simya, O., A. Mahaboobbatcha, and K. Balachander, A comparative study on the performance of Kesterite based thin film solar cells using SCAPS simulation program. Superlattices and Microstructures, 2015. 82: p. 248-261.

41. Mohammadnejad, S., Z.M. Bahnamiri, and S.E. Maklavani, Enhancement of the performance of kesterite thin-film solar cells using dual absorber and ZnMgO buffer layers. Superlattices and Microstructures, 2020. 144: p. 106587.

42. Adewoyin, A.D., M.A. Olopade, and M. Chendo, Prediction and optimization of the performance characteristics of CZTS thin film solar cell using band gap grading. Optical and Quantum Electronics, 2017. 49(10): p. 1-13.

43. Shur, M.S., Handbook series on semiconductor parameters. Vol. 1. 1996: World Scientific.

44. Ramli, N.F., et al. Model development of monolithic tandem silicon-perovskite solar cell by SCAPS simulation. in AIP Conference Proceedings. 2017. AIP Publishing LLC.

45. Hasan, M., et al. Modeling of high efficient perovskite-Si tandem solar cell. in 2017 3rd International Conference on Electrical Information and Communication Technology (EICT). 2017. IEEE.

46. Adachi, S. and P. Properties, Compiled Experimental Data,// Copp. Zinc Tin Sulfide-Based Thin-Film Sol. Cells, 2015: p. 149-179.

47. Burgelman, M., et al., SCAPS manual. February, 2016.

48. Krc, J., Optical modeling and simulation of thin-film photovoltaic devices. 2013: Crc Press.

49. Kim, K., et al., Performance prediction of chalcopyrite-based dual-junction tandem solar cells. Solar Energy, 2017. 155: p. 167-177.

50. Burdick, J. and T. Glatfelter, Spectral response and IV measurements of tandem amorphous-silicon alloy solar cells. Solar Cells, 1986. 18. 
51. Liao, X., X. Xiang, and X. Zeng. Modeling analyses for current matching in tandem solar cells. in IEEE International Conference on Electro-Information Technology, EIT 2013. 2013. IEEE.

\section{Figures}
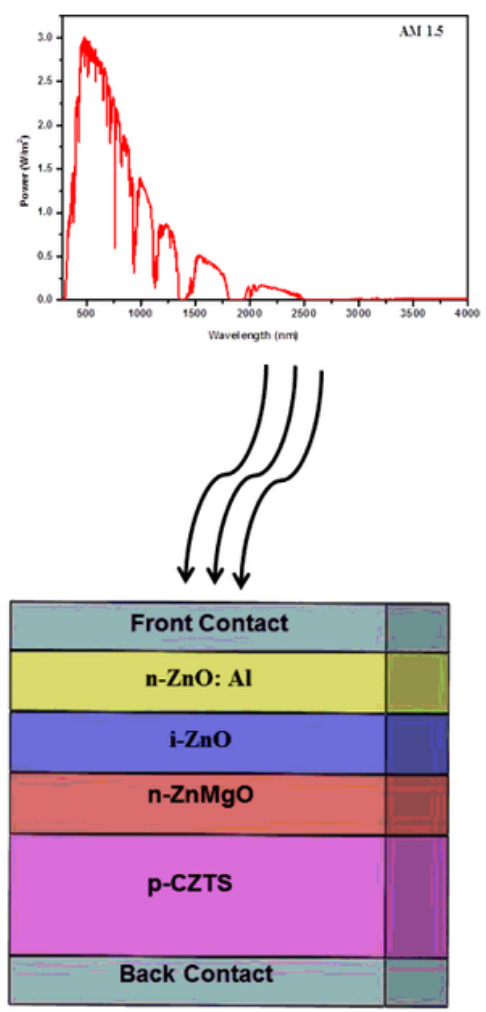

(a)
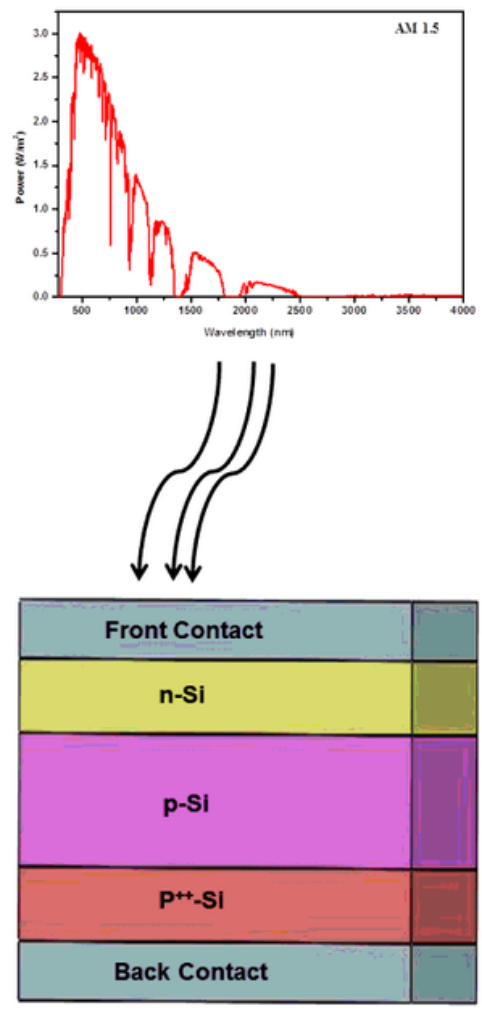

(b)

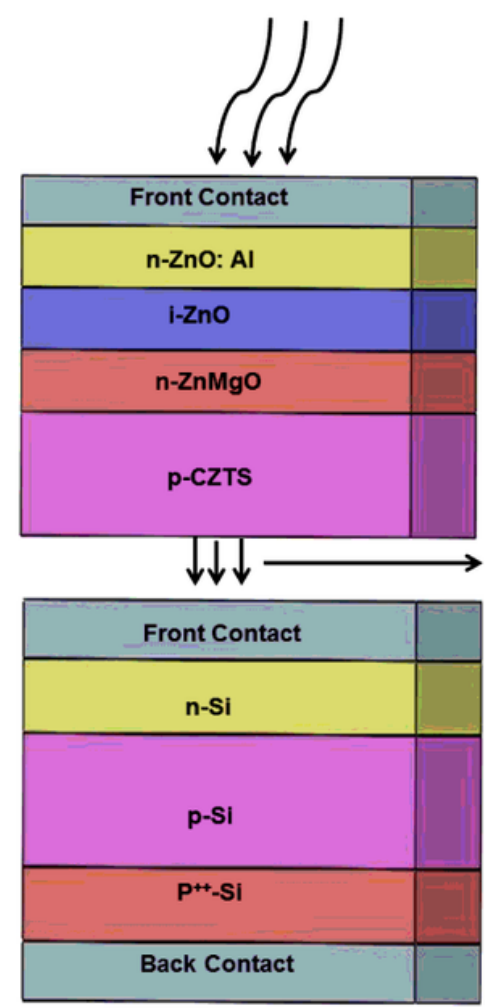

(c)
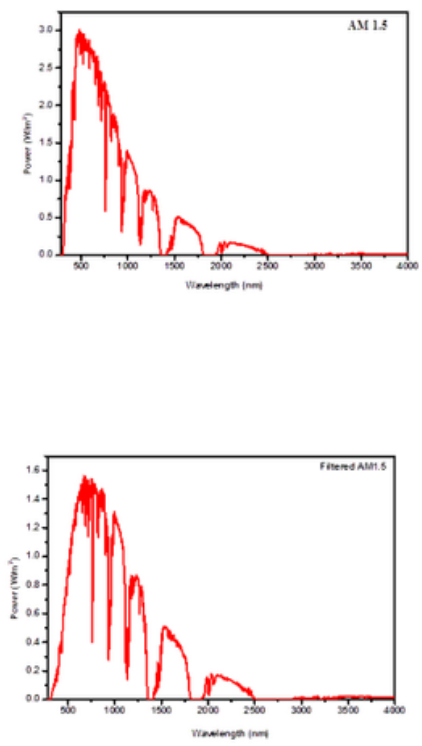

\section{Figure 1}

a) 3D representation of upper subcell at AM1.5 illumination; b) 3D representation of Lower subcell at AM1.5 illumination; c) 3D representation of tandem device at AM1.5 illumination on upper subcell and transmitted spectrum from the upper cell is used to simulate lower subcell. 


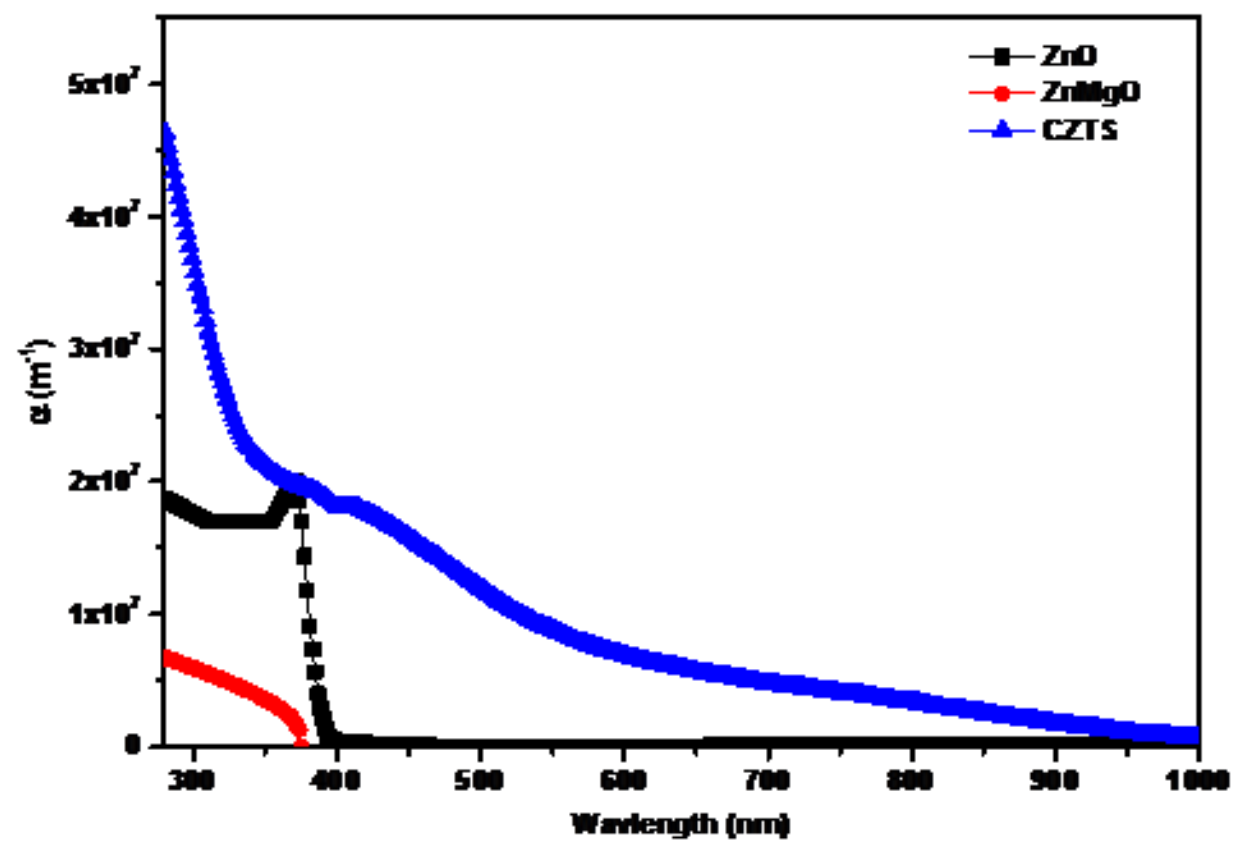

Figure 2

Absorption coefficient profile of upper subcell used for transmitted spectrum

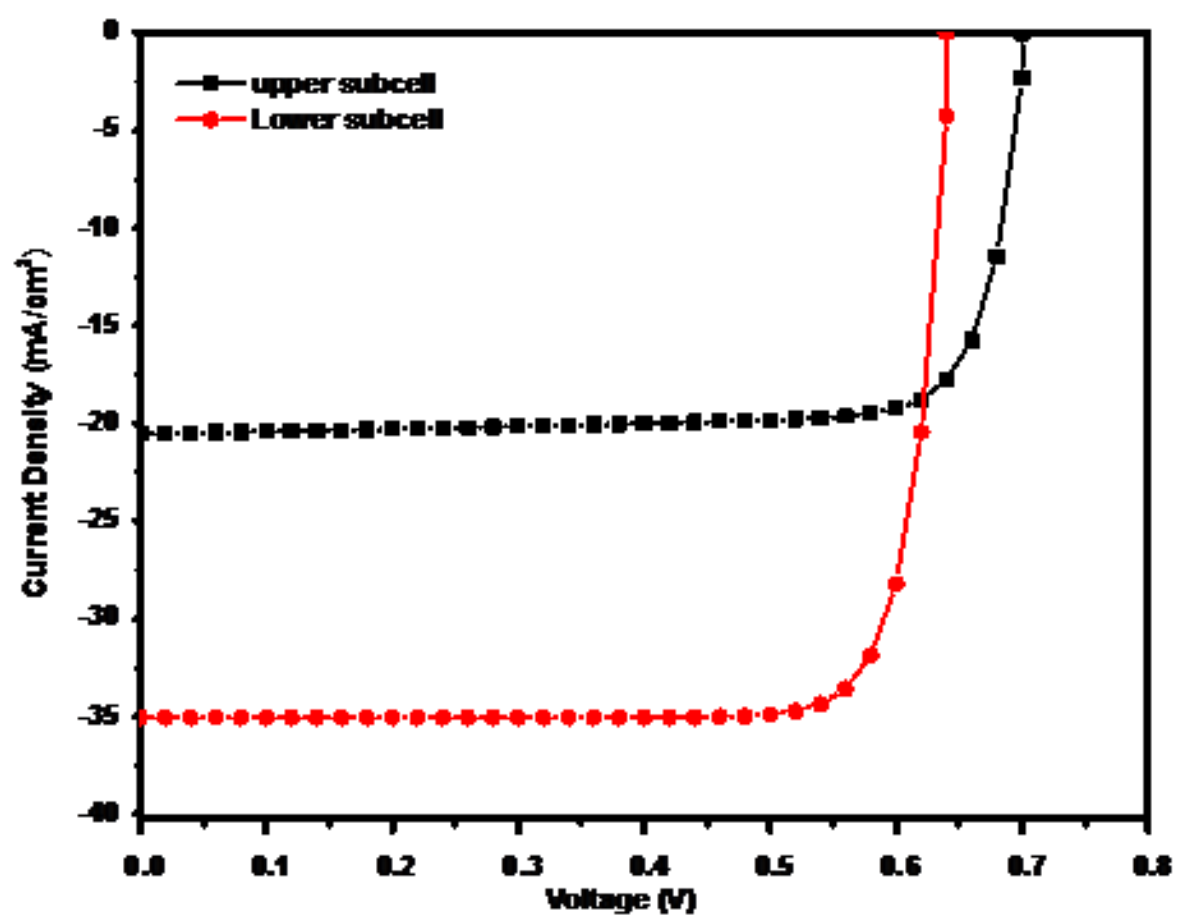

Figure 3

$\mathrm{J}-\mathrm{V}$ of single-junction upper and lower subcell at AM1.5 illumination 

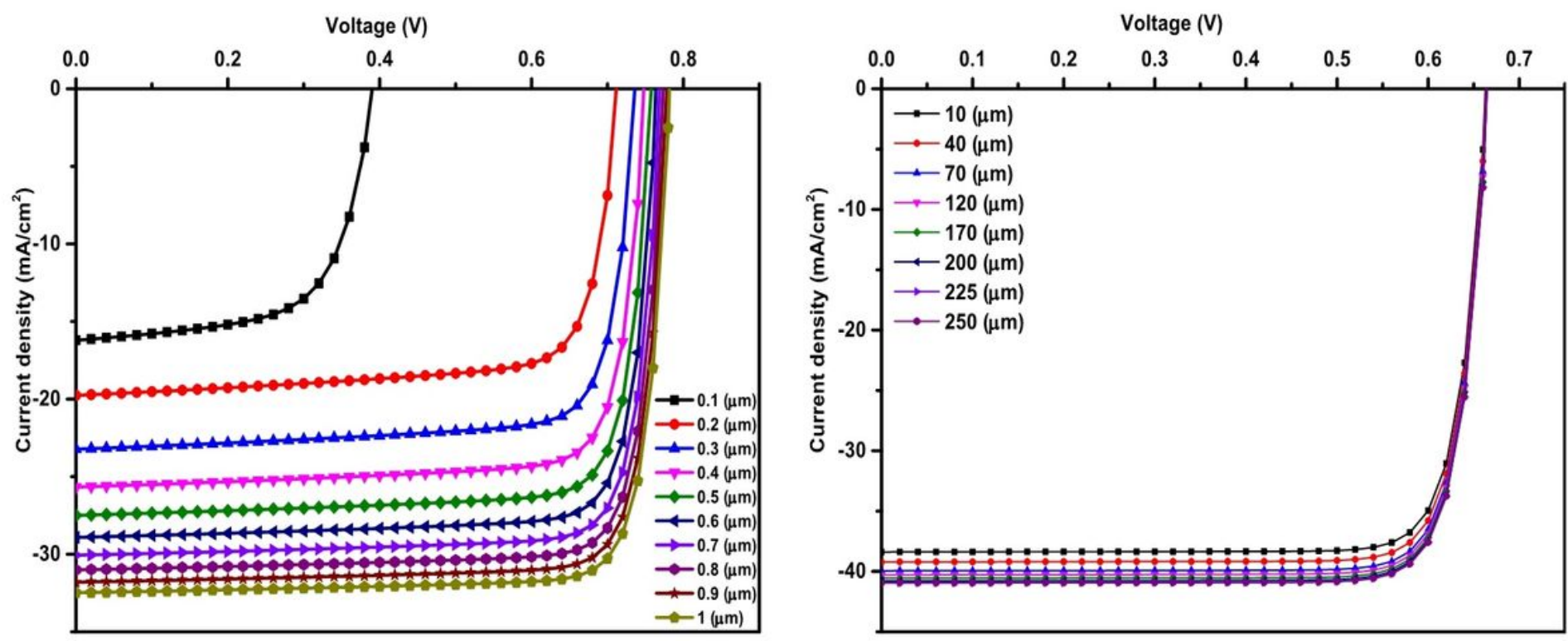

Figure 4

$\mathrm{J}-\mathrm{V}$ curve of upper and lower cell variation with the thickness of absorber layer
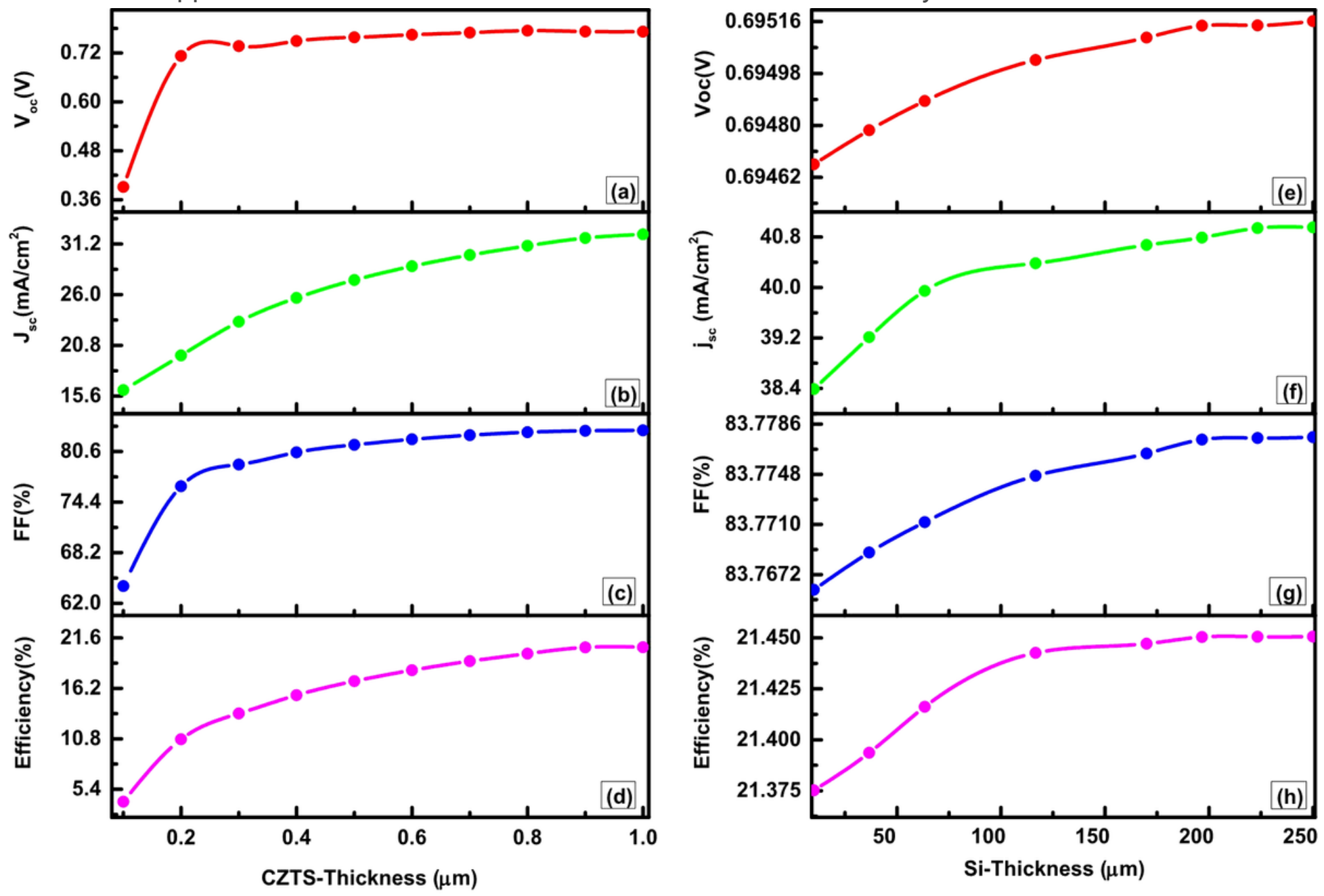


\section{Figure 5}

PV parameter of single-junction (a-d) upper subcell and (e-h) lower subcell with different absorber layer thickness at 1.5AM illumination; $(a, e)$ VOC $(b, f)$ JSC $(c, g)$ FF $(d, h)$ PCE.

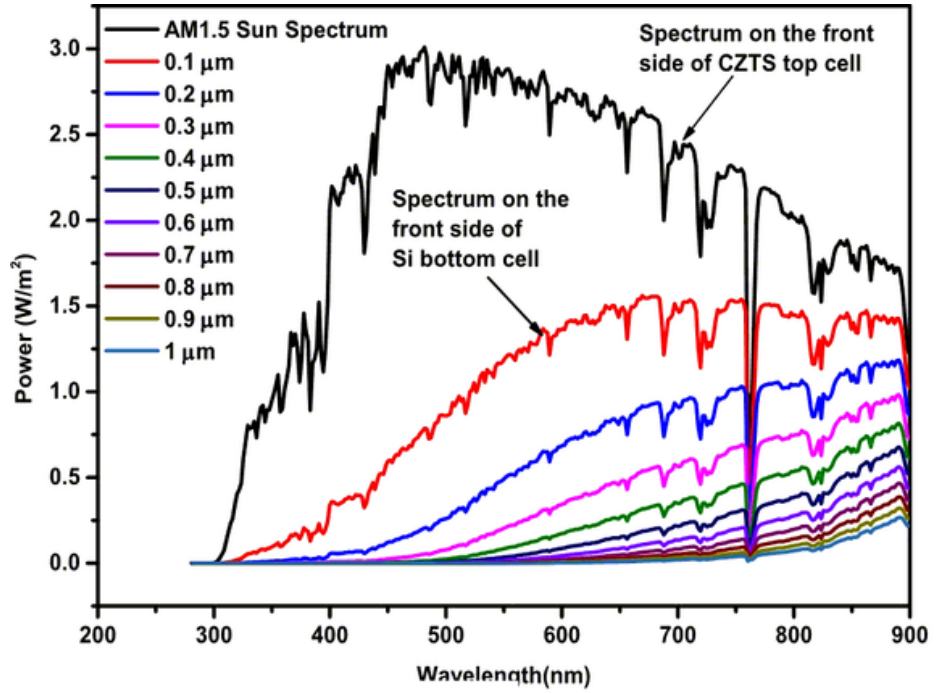

(a)

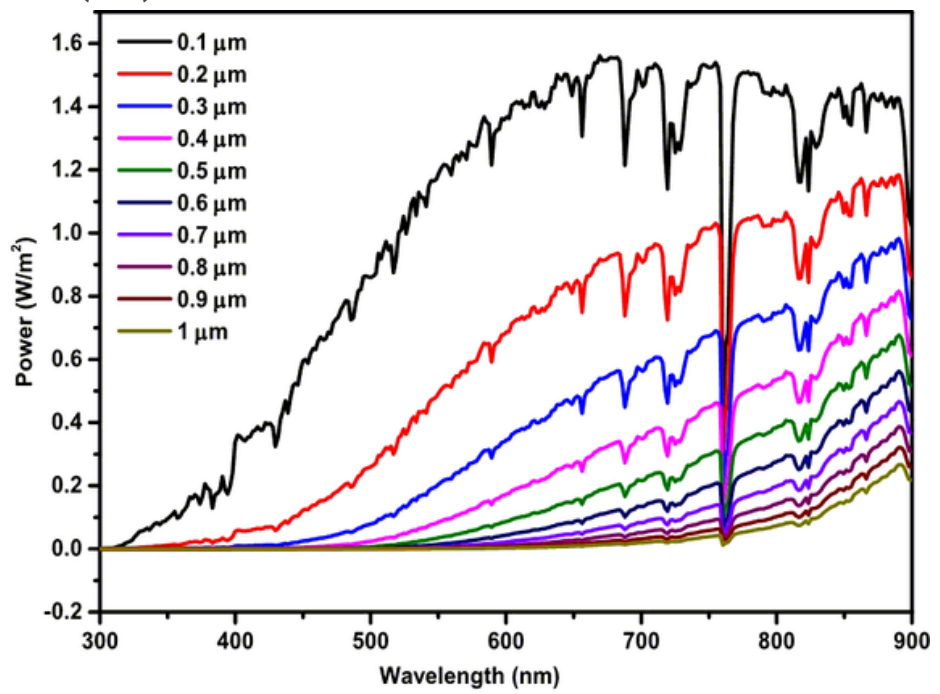

(b)

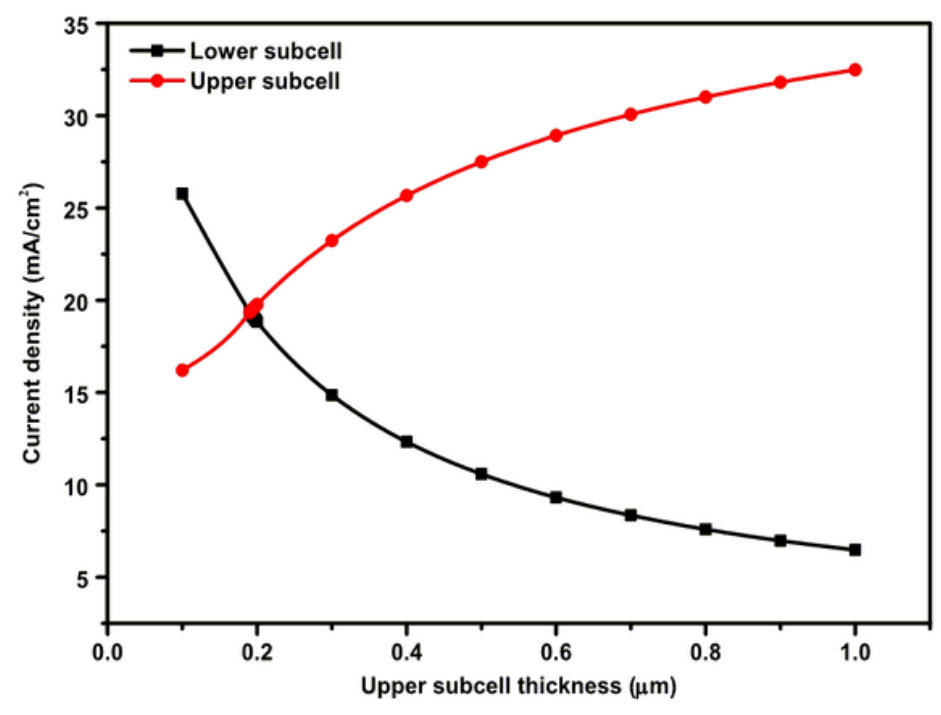

(c)

\section{Figure 6}

a) AM1.5 spectrum with transmitted b) Computed transmitted spectrums for lower subcell c) Optimized of upper and lower subcell Jsc with the variation of upper subcell thickness 


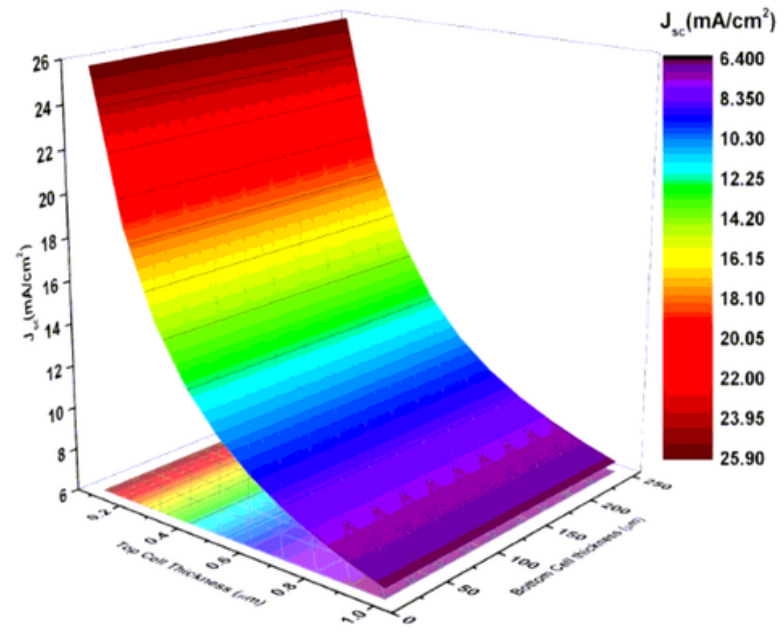

(a)

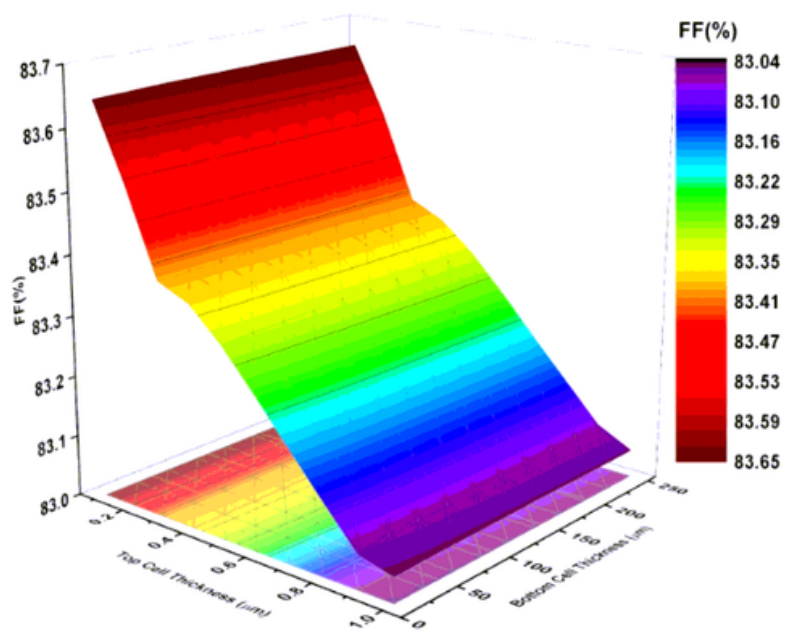

(c)

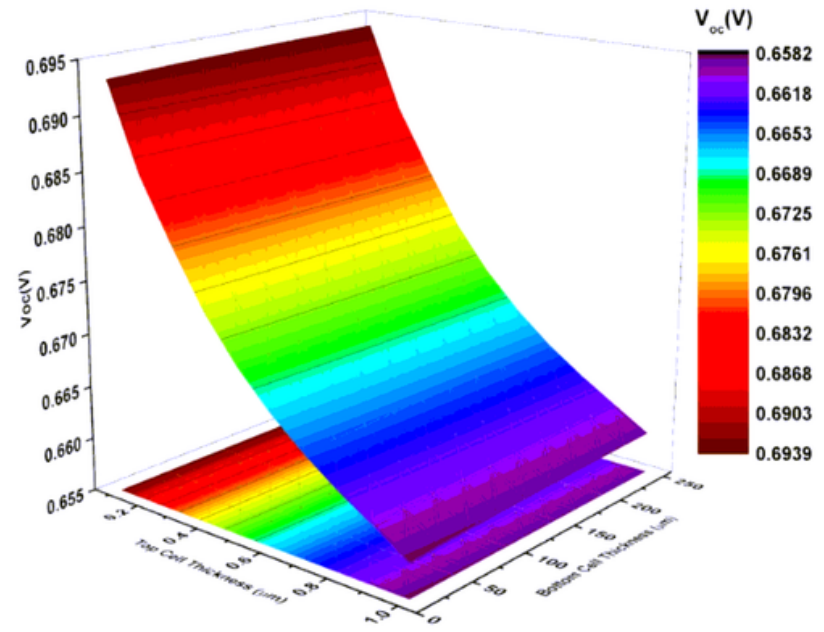

(b)

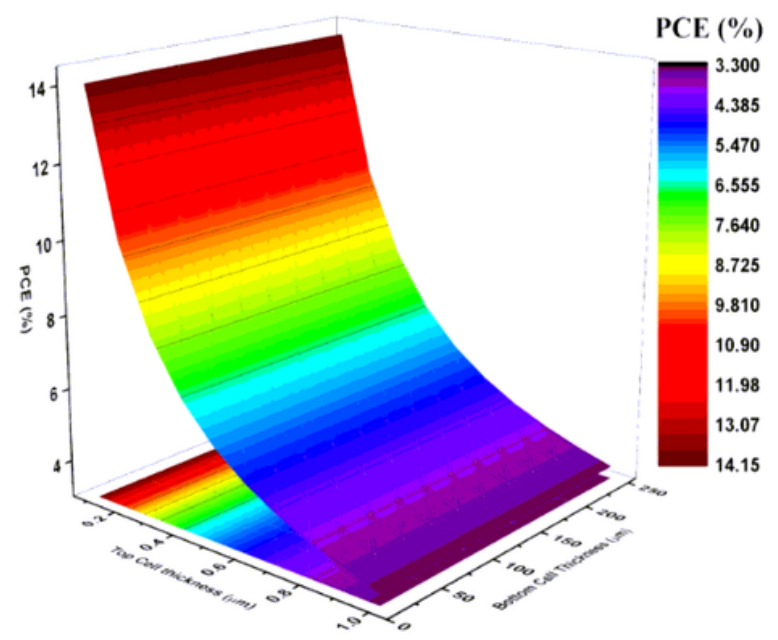

(d)

\section{Figure 7}

3-D contour plots for a lower subcell with the variation Silicon absorber layer thickness under transmitted spectra (a) Current density (b) open circuit Voltage (c) fill factor (d) efficiency 


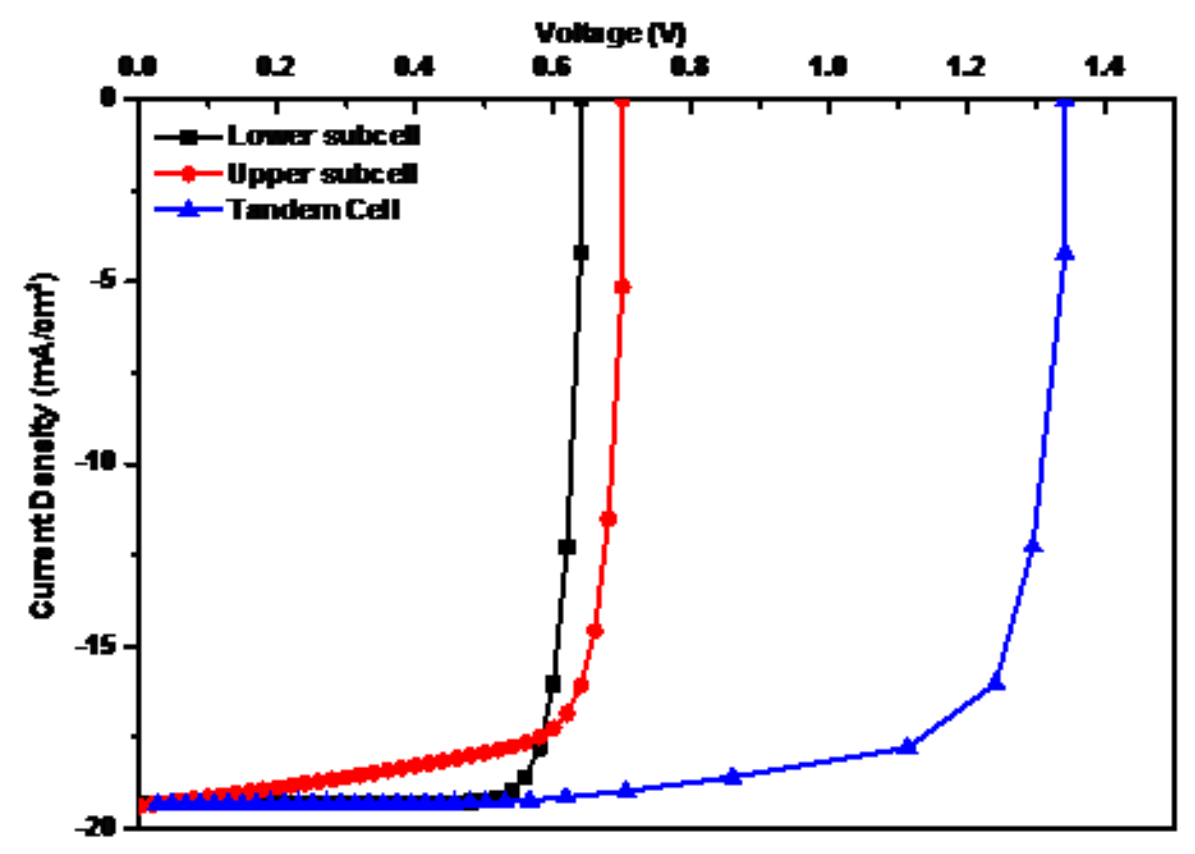

Figure 8

$\mathrm{J}-\mathrm{V}$ curve of the optimized upper, lower, and tandem solar cell 